\title{
Prevalence of Intestinal Parasites and Associated Factors among Adult Pre-ART and ART Patients in Goncha Siso Enesie Woreda, East Gojjam, Northwest Ethiopia, 2014
}

\section{Tadesse Asmare ${ }^{1}$, Worku Awoke ${ }^{2}$ and Girma Alem ${ }^{3 *}$}

${ }^{1}$ Onchocerciasis Elimination Program Researcher, Carter Center, Addis Ababa, Ethiopia

${ }^{2}$ Department of Epidemiology, School of Public Health, College of Medicine and Health Sciences, Bahir Dar University, Ethiopia

${ }^{3}$ Department of Nursing, College of Health Sciences, Debremarkos University, Ethiopia

\begin{abstract}
Background: The prevalence of opportunistic intestinal parasites is expected to be high among Human Immune Deficiency Virus infected populations in developing countries. For many years, intestinal infections caused by opportunistic organisms have been represented as a major problem in immune compromised patients with Acquired Immune Deficiency Syndromes.
\end{abstract}

Methods: Institution based comparative cross sectional study design was conducted in Gendewoyn health center, Goncha Siso Enesie woreda from March to June 2014. A structured questionnaire was administered to all participants to obtain information on socio demographic characteristics and their source of drinking water. For the laboratory test using a direct saline, Dobell's iodine separate wet mount, formal ether concentration and modified Ziehl-Neelsen (Zn) method was applied. The minimum sample size for this quantitative study was 312 . Binary and multiple logistic regressions were used to identify factors of intestinal parasite infection and odds ratios, $95 \% \mathrm{Cl}$ and $\mathrm{p}$-value were computed to measure the presence and strength of associations.

Results: The overall prevalence of intestinal parasite infections in pre-ART and on-ART was $53.7 \%$ and $36.5 \%$, respectively with significant decrease of intestinal parasite in the ART era $(p<0.006)$. Majority of Cryptosporidium species infections were found in the pre-ART patients and significantly associated for lower CD4<500 cells $/ \mathrm{mm}^{3}$. Absence of toilet $(A O R=1.80 ; 95 \% \mathrm{Cl}=1.090-2.975)$, source of water $(A O R=8.260 ; 95 \% \mathrm{Cl}=4.659-14.642)$, rural residence $(A O R=2.292,95 \% \mathrm{Cl}=1.386-3.788)$; $\mathrm{CD} 4$ counts $(\mathrm{AOR}=1.559 ; 95 \% \mathrm{Cl}=1.093-2.722)$ HAART status: pre ART patients $(A O R=2.13, \mathrm{Cl}, 1.167-3.905)$ have significant association with prevalence of intestinal parasite infections.

Conclusion and recommendations: The most prevalent parasite in the pre-ART subjects were ova of Ascaris lumbricoides (15.7\%) followed by Enteamoeba histolytica (14.8\%) while on ART patients the most prevalent parasites were ova of Ascaris lumbricoides (8.8\%) and cyst of Enteamoeba histolytica (7.4\%). The present study revealed the importance of examining pre-ART and on ART patients for intestinal parasite infections. This study reminded health professionals regarding the occurrence of these parasites in this population. Routine examination of stool samples for parasitic infections could significantly benefit pre-ART and on ART patients for early treatment.

Keywords: Parasites; Pre-ART; ART; Modified Ziehl-Neelsen

Abbreviations: AIDS: Acquired Immune Deficiency Syndrome; AOR: Adjusted Odds Ratio; ART: Anti-Retroviral Therapy; BSC: Bachelor of Science; CD4+ T: Cluster of Differentiation of T lymphocytes; COR: Crude Odds Ratio; EDHS: Ethiopian Demographic and Health Surveys; HAART: Highly Active Anti retro Viral Therapy; HIV: Human Immune Deficiency Virus; IPIs: Intestinal Parasite Infections; IPs: Intestinal Parasites; km: kilometers; spp.: species; SPSS: Statistical packages for social sciences; Ul: Micro Liter; UNAIDS: United nation Acquired Immune Deficiency Syndrome; WHO: World Health Organization

\section{Introduction}

\section{Background information}

Human Immune Deficiency Virus/Acquired Immune Deficiency Syndrome disease is a chronic infectious disease caused by the Human Immune Deficiency Virus, which is characterized by spectrum starting from primary infection, with or without the acute syndrome, followed by a relatively long period of asymptomatic stage after which in most patient's progress to advanced and life threatening disease [1].

Intestinal parasitic infections are distributed virtually throughout the world, with high prevalence rates in many regions. Amoebiasis,
Ascariasis, Hookworm infection and Trichuriasis are among the ten most common infections in the world [2].

Intestinal parasites are parasites that populate the gastro-intestinal tract in humans and other animals. These parasites can live throughout the body, but most prefer the intestinal wall. The two main types of intestinal parasites are helminthes and protozoa. The major groups of parasites include protozoa's and parasitic worms (helminths). Of these, protozoans, including Cryptosporidium, Microsporidia and Isospora, are most common in HIVinfected persons. Each of these parasites can infect the digestive tract and sometimes two or more can cause infection at the same time [3].

*Corresponding author: Girma Alem, (BSC, MSC), Nursing Department Health Science College, Debremarkos University, Debremarkos, Ethiopia; Tel: 251910685241; E-mail: girmaalem95@gmail.com

Received July 08, 2017; Accepted September 25, 2017; Published October 03 2017

Citation: Asmare T, Awoke W, Alem G (2017) Prevalence of Intestinal Parasites and Associated Factors among Adult Pre-ART and ART Patients in Goncha Siso Enesie Woreda, East Gojjam, Northwest Ethiopia, 2014. J AIDS Clin Res 8: 734 doi: 10.4172/2155-6113.1000734

Copyright: (C) 2017 Asmare T, et al. This is an open-access article distributed under the terms of the Creative Commons Attribution License, which permits unrestricted use, distribution, and reproduction in any medium, provided the original author and source are credited. 
For many years, intestinal infections caused by opportunistic organisms have represented a major problem in immune compromised patients with AIDS. In western countries a decreased incidence of parasitic intestinal infection has been registered as a result of immunological reconstitution in patients receiving HAART. In developing countries where antiretroviral treatments are not available IPIs were still play a major role in the morbidity and mortality of AIDS patients. In Sub-Saharan Africa diarrheal disease and AIDS take the fourth and first place among the leading causes, burden and death, respectively [4]. Recent studies have shown that parasitic infections could disturb the balance of anti-HIV immune responses and contributed to HIV replication [5].

\section{Statement of the problem}

Globally, an estimated 35.3 million people were living with HIV in 2012. An increased from previous years as more people are receiving the life-saving antiretroviral therapy. There were 2.3 million new HIV infections globally, showing a $33 \%$ decline in the number of new infections from 3.4 million in 2001. At the same time the number of AIDS deaths is also declining with 1.6 million AIDS deaths in 2012, down from 2.3 million in 2005. Sub-Saharan Africa still bears a disproportionate share of the global HIV burden. It accounts $68 \%$ of the global HIV burden in 2012 [6].

In 2012, 9.7 million people in low- and middle-income countries received antiretroviral therapy, representing $61 \%$ of all who were eligible under the 2010 World Health Organization HIV treatment guidelines. However, under the 2013 WHO guidelines, the HIV treatment coverage in low- and middle-income countries represented only $34 \%$ of the 28.6 million people eligible in 2013. Antiretroviral therapy not only prevents AIDS-related illness and death: it also has the potential to significantly reduce the risk of HIV transmission and the spread of tuberculosis. From 1996 to 2012, antiretroviral therapy averted 6.6 million AIDSrelated deaths worldwide, including 5.5 million deaths in low- and middle-income countries. But despite historic gains in expanding treatment services, efforts to reach universal treatment access face considerable challenges [7]. Ethiopian Demographic and Health Survey 2011 report showed the national over all prevalence of HIV/AIDS is $1.5 \%[8]$

Parasitic infections, caused by intestinal helminths and protozoan parasites, are among the most prevalent infections in humans in developing countries. In developed countries, protozoan parasites more commonly cause gastrointestinal infections compared to helminths. Intestinal parasites cause a significant morbidity and mortality in endemic countries [9]. The public health importance of intestinal parasites in most developing countries has become prominent with the co-occurrence of malnutrition and HIV/AIDS. Due to lack of appropriate handling of food and drinking water, the prevalence of opportunistic intestinal parasites is expected to be high among HIV infected populations in developing countries [10]. Almost $80 \%$ of AIDS patients die from AIDS-related infections including intestinal parasites rather than HIV infection itself [11].

\section{Significance of the study}

This study provides body of knowledge of intestinal parasite prevalence of pre-ART and ART patients in health centers and provides information about associated factors towards IP prevalence among HIV/AIDS patients. It also provides information for the clinicians and the woreda health office to care their patients. Finally it my serve as a stepping stone for further studies.

\section{Objectives}

\section{General objective}

To compare prevalence of intestinal parasites and associated factors among adult pre-ART and on ART patients in Goncha Siso Enesie Woreda, East Gojjam, Northwest Ethiopia, 2014

\section{Specific objectives}

- To compare prevalence of IP in adult HIV/AIDS patients who are pre-ART and on ART.

- To identify associated factors for IP prevalence of adult preARTand on ART patients.

\section{Materials and Methods}

\section{Study area}

The study was conducted in Goncha Siso Enesie Woreda which has a population of 165,218 (Source: 2005 woreda health office report). There are 38 health posts and 7 health centers in the woreda. Only one health center provides ART service with a total client of 222 preART patients and 453 on ART patients in the woreda. The ART clinic provides the service for a total of 675 pre ART and on ART clients. One BSC nurse and one diploma clinical nurse who took basic ART training provides the service (Source: 2005 Goncha Siso Enesie woreda. health office report).

\section{Study design}

Comparative cross sectional study design was conducted in Gendewoyn health center, Goncha Siso Enesie Woreda conducted from March to June 2014.

\section{Source population}

The source population was all HIV/AIDS patients in Goncha Siso Enesie Woreda.

\section{Study population}

Adult HIV/AIDS patients in pre ART and on ART who came to Gendewoyn Health Center during the data collection period.

\section{Sample size determination}

The required sample size of the study participants was determined by double population proportion formula. Assumptions; $\mathrm{Z}=$ standardized normal distribution value for the $95 \% \mathrm{CI}$, which is 1.96 for sample size determination. Proportion taken from previous study: Dessie Hospital; Proportion of pre-ART (p1)=39\%, Proportion of on-ART $(\mathrm{p} 2)=17.6 \%$, (20) Marginal error $(\mathrm{w})=5 \%$.

\section{Double population proportion}

$\mathrm{Z} \alpha / 2=1.96$, type one error $5 \%$

$\mathrm{Z} \beta=0.84,80 \%$ power

P1: IP prevalence of pre ART HIV/AIDS patients=39\%,

P2: IP prevalence of on ART HIV/AIDS patients=17.6,

$\mathrm{r}=1 / 2$ (one part of pre ART HIV+ and two part on ART HIV+ patients will be used)

$\mathrm{p}=\mathrm{p} 1+\mathrm{rp} 2 / \mathrm{r}+1,0.39+0,5(0.176) / 1+0.5=0.478 / 1.5=0.3186$ 


$$
\frac{\mathrm{n} 1=\left[\alpha 1 / 2 \sqrt{ }(1+1 / \mathrm{r}) \mathrm{p}(1-\mathrm{p})+{ }^{\beta} \sqrt{ } \mathrm{p} 1(1-\mathrm{p} 1)+\mathrm{p} 2(1-\mathrm{p} 2) / \mathrm{r}\right] 2}{(\mathrm{P} 1-\mathrm{p} 2) 2}
$$

This gives 104 pre ART and 208 on ART patients.

A total sample size of 312 was used.

\section{Sampling procedure}

The study was conducted in Goncha Siso Enesie Woreda which was selected purposively. Gendewoyn Health Center is the only health center in the Woreda that provides the ART service and selected for the study. The sampling procedure was by using consecutive sampling. There were 675 pre ART and on ART HIV/AIDS patients. By dividing 675 to 312 it gives 2. Every other adult pre-ART and on ART patients who came to the ART clinic to pick up their ART drug during the data collection period (from January to February2014) were included.

\section{Inclusion criteria}

HIV/AIDS patients of age $\geq 18$ years who were available at the data collection period in Gendewoyn Health Center and were willing to participate in the study.

\section{Exclusion criteria}

Patients who live less than 6 months in the woreda during the study period.

\section{Variables}

Dependent variables: Prevalence of IP among adult HIV/AIDS patients.

Independent variables: Age, sex, CD4+ T lymphocyte counts, source of drinking water, place of residence, WHO staging, level of education, ART status (pre-ART or on ART), presence or absence of latrine.

\section{Data collection procedure}

A structured questionnaire was administered to all participants to obtain information on socio demographic characteristics and their source of drinking water. The questionnaire was pretested on $10 \%$ of the size of the study participants before one week of the actual study in Enebsie Sar Midir Woreda, Mertolemariam (name of neighboring woreda health center) Health Center ART clinic.

\section{Data collection instrument}

Structured questionnaire was administered to all participants to obtain on socio demographic characteristics and their source of drinking water. Laboratory results were obtained from microscopic observation.

Personnel: The research team included principal investigator, two laboratory technicians for laboratory investigation, one BSC nurse and one clinical nurse who work in the ART clinic for interviewing, two supervisors and two advisors from Debre Markos University.

\section{Laboratory procedure}

Stool collection and examination for laboratory was supervised and checked by the principal investigator. Fresh stool was collected by wide mouthed clean cup. The stool examination was performed in three ways. A direct saline and Dobell's iodine separate wet mount was examined $\mathrm{x} 10$ and $\mathrm{x} 40$ objective for the presence of helminthes, flagellates and cysts of flagellates. Formal ether concentration (for low concentrated parasites in stool) and formal ether concentration (for oocyst of Cryptosporidium parvum and Isospora belli) was performed [12].

Data quality and laboratory test assurance: The quality of data on socio demographic characteristics and their source of drinking water were assured by proper designing and pre-testing of the structured questionnaires. Training was given for data collectors, supervisors and laboratory examiners by the principal investigator for a day before and one day after pretest. The training included discussion on the objectives, contents of the questionnaire, procedures, data collection techniques, labeling, laboratory result writing training and confidentiality of the responses. Every day after data collection, questionnaires were reviewed and checked for completeness by the supervisors and principal investigator. Based on the review the necessary feedback was offered to data collectors in the next morning. Laboratory reagents were tested using known positive and negative samples for the sensitivity and specificity of the test. Each laboratory procedure, test, labeling, and laboratory result writing training was given for the laboratory personnel.

\section{Ethical consideration}

The thesis was reviewed and approved by Medicine and Health Science College Review Committee and permission to conduct this study was obtained from Goncha Siso Enesie Woreda Health Office. All selected participants were asked and informed about the study and laboratory test in order to obtain their verbal consent before administering questionnaires and laboratory tests. Participants were also informed that they have full right to discontinue or refuse to participate in the study. They were also informed that all data obtained from them was kept confidential. Intestinal parasite tested positive patients were treated by dealing with the health center head and by the researcher.

\section{Results}

\section{Socio-demographic characteristics of the study participants}

A total of 312 study adult participants both pre-ART and on ART from Gendewoyn health center were examined for intestinal parasite infections. Adult Pre ART study participants comprised 108 (34.6\%) and the remaining adults 204 (65.4\%) were on ART. The sex distribution of participants showed majority of pre-ART 78 (72.2\%) were females. On the ART group 144 (70.6\%) were females.

The age range of the study participants $48(44.4 \%)$ of pre ART participants were in the age range of $25-34$ years and $28(25.9 \%)$ were in the age range of 18-24 years. On the ART group $82(40.2 \%)$ were in the age range of $25-34$ years and $66(32.4 \%)$ were in the age range of 35-44 years.

Majority of the study participants 48 (44.4\%) and 85 (41.7\%) were farmers on pre ART and on ART, respectively. Their educational distribution showed that $68(63 \%)$ and 135 (66.2\%) pre ART and on ART subjects were unable to read and write respectively (Tables 1 and 2).

\section{Prevalence of intestinal parasites in pre ART and on ART study participants}

A total of 312 stool samples both from pre ART and on ART study participants were collected and examined for intestinal parasites. During microscopic examination of stool samples eleven types of intestinal parasites were identified. The most frequently detected parasites were A. Lumbricoides (11.2\%) and Enteamoeba histolytica/dispar (10.9\%) (Table 3). 
Citation: Asmare T, Awoke W, Alem G (2017) Prevalence of Intestinal Parasites and Associated Factors among Adult Pre-ART and ART Patients in Goncha Siso Enesie Woreda, East Gojjam, Northwest Ethiopia, 2014. J AIDS Clin Res 8: 734. doi: 10.4172/2155-6113.1000734

Page 4 of 8

\begin{tabular}{|c|c|c|c|c|c|c|c|}
\hline \multirow{2}{*}{\multicolumn{2}{|c|}{ Variables }} & \multicolumn{2}{|c|}{$\begin{array}{c}\text { Pre-ART } \\
n=108\end{array}$} & \multicolumn{2}{|c|}{$\begin{array}{c}\text { On ART } \\
n=204\end{array}$} & \multicolumn{2}{|c|}{$\begin{array}{c}\text { Total } \\
n=312\end{array}$} \\
\hline & & \multirow{2}{*}{$\begin{array}{c}\text { Frequency } \\
30\end{array}$} & \multirow{2}{*}{$\begin{array}{c}\text { Percent } \\
27.8\end{array}$} & \multirow{2}{*}{$\begin{array}{c}\text { Frequency } \\
60\end{array}$} & \multirow{2}{*}{$\begin{array}{c}\text { percent } \\
29.4\end{array}$} & \multirow{2}{*}{$\begin{array}{c}\text { Frequency } \\
90\end{array}$} & \multirow{2}{*}{$\begin{array}{c}\text { Percent } \\
28.8\end{array}$} \\
\hline Sex & Male & & & & & & \\
\hline & Female & 78 & 72.2 & 144 & 70.6 & 222 & 71.2 \\
\hline \multirow[t]{4}{*}{ Age } & $18-24$ & 28 & 25.9 & 16 & 7.8 & 44 & 14.1 \\
\hline & $25-34$ & 48 & 44.4 & 82 & 40.2 & 130 & 41.7 \\
\hline & $35-44$ & 22 & 20.4 & 66 & 32.4 & 88 & 28.2 \\
\hline & $>44$ & 10 & 9.3 & 40 & 19.6 & 50 & 16 \\
\hline \multirow[t]{2}{*}{ Residence } & Urban & 45 & 41.7 & 102 & 50 & 165 & 52.9 \\
\hline & Rural & 63 & 58.3 & 102 & 50 & 95 & 47.1 \\
\hline \multirow{6}{*}{ Occupation } & Government employed & 4 & 3.7 & 6 & 3 & 10 & 3.2 \\
\hline & Farmer & 48 & 44.4 & 88 & 43 & 136 & 43.6 \\
\hline & Student & 8 & 7.4 & 5 & 2.5 & 13 & 4 \\
\hline & Merchant & 24 & 22.3 & 51 & 25 & 75 & 24 \\
\hline & Unemployed & 7 & 6.5 & 14 & 7 & 21 & 6.7 \\
\hline & Daily laborers & 17 & 15.7 & 40 & 19.5 & 57 & 18 \\
\hline \multirow{4}{*}{ Educational status } & Cannot read and write & 68 & 63.0 & 135 & 66.1 & 203 & 65 \\
\hline & Can read and write & 32 & 29.6 & 56 & 27.5 & 88 & 28 \\
\hline & Secondary school & 5 & 4.6 & 11 & 5.4 & 16 & 5 \\
\hline & College and above & 3 & 2.8 & 2 & 1.0 & 5 & 2 \\
\hline \multirow{4}{*}{ Religion } & Orthodox & 108 & 100 & 204 & 100 & 312 & 100 \\
\hline & Muslim & 0 & 0 & 0 & 0 & 0 & 0 \\
\hline & Protestant & 0 & 0 & 0 & 0 & 0 & 0 \\
\hline & others & 0 & 0 & 0 & 0 & 0 & 0 \\
\hline \multirow[t]{4}{*}{ Ethnicity } & Amhara & 108 & 100 & 204 & 100 & 312 & 100 \\
\hline & Oromo & 0 & 0 & 0 & 0 & 0 & 0 \\
\hline & Tigray & 0 & 0 & 0 & 0 & 0 & 0 \\
\hline & Others & 0 & 0 & 0 & 0 & 0 & 0 \\
\hline
\end{tabular}

Table 1: Socio demographic characteristics of adult pre- ART and on ART HIVIAIDS patients in Gendewoyn Health Center March to June, 2014.

\begin{tabular}{|c|c|c|c|c|c|c|c|}
\hline \multicolumn{2}{|l|}{ Variables } & \multicolumn{2}{|c|}{ Pre-ART $n=108$} & \multicolumn{2}{|c|}{ On ART $n=204$} & \multicolumn{2}{|c|}{ Total $n=312$} \\
\hline CD4 count & $<=500$ & $\begin{array}{c}\text { Frequency } \\
40\end{array}$ & $\begin{array}{c}\text { Percent } \\
37.0\end{array}$ & $\begin{array}{c}\text { Frequency } \\
54\end{array}$ & $\begin{array}{c}\text { Percent } \\
26.5\end{array}$ & $\begin{array}{c}\text { Frequency } \\
94\end{array}$ & $\begin{array}{c}\text { Percent } \\
30.1\end{array}$ \\
\hline & $>500$ & 68 & 63.0 & 150 & 73.5 & 218 & 69.9 \\
\hline \multirow[t]{4}{*}{ WHO staging } & Stage 1 & 21 & 19.4 & 40 & 19.6 & 61 & 19.6 \\
\hline & Stage 2 & 40 & 37.0 & 63 & 30.9 & 103 & 33 \\
\hline & Stage3 & 43 & 39.8 & 87 & 42.6 & 130 & 41.4 \\
\hline & Stage4 & 4 & 3.7 & 14 & 6.9 & 18 & 6 \\
\hline \multirow[t]{2}{*}{ Access of latrine } & Yes & 54 & 50 & 112 & 54.9 & 166 & 53.2 \\
\hline & No & 54 & 50 & 92 & 45.1 & 146 & 46.8 \\
\hline \multirow{3}{*}{ Eat raw meat } & Yes always & 5 & 4.6 & 2 & 0.9 & 7 & 2.2 \\
\hline & Yes sometimes & 101 & 93.5 & 8 & 3.8 & 109 & 34.9 \\
\hline & No & 2 & 1.9 & 194 & 95.3 & 196 & 62.9 \\
\hline \multirow{2}{*}{$\begin{array}{l}\text { Source of drinking } \\
\text { water }\end{array}$} & Tape water protected & 48 & 44.4 & 114 & 55.9 & 162 & 52 \\
\hline & River water unprotected & 60 & 55.6 & 90 & 44.1 & 150 & 48 \\
\hline \multirow{3}{*}{ Shoes wearing } & Yes I wear it always & 27 & 25 & 99 & 48.5 & 126 & 40.4 \\
\hline & Yes I sometimes wear it & 71 & 65.7 & 84 & 41.2 & 155 & 49.6 \\
\hline & No & 10 & 9.3 & 21 & 10.3 & 31 & 10 \\
\hline \multirow{3}{*}{$\begin{array}{l}\text { Eat raw } \\
\text { vegetables }\end{array}$} & Yes always & 3 & 3 & 4 & 2 & 7 & 2.4 \\
\hline & Yes sometimes & 1 & 0.9 & 1 & 0.5 & 2 & 0.6 \\
\hline & No & 104 & 96.1 & 199 & 97.5 & 303 & 97 \\
\hline \multirow{2}{*}{$\begin{array}{l}\text { Type of your } \\
\text { housing }\end{array}$} & Cemented wall and floor & 1 & 0.9 & 1 & 0.5 & 2 & 0.6 \\
\hline & $\begin{array}{l}\text { Un cemented wall and } \\
\text { floor }\end{array}$ & 107 & 99.1 & 203 & 99.5 & 310 & 99.4 \\
\hline \multirow{2}{*}{$\begin{array}{l}\text { Boiling drinkable } \\
\text { water }\end{array}$} & Yes & 1 & 0.9 & 2 & 0.9 & 3 & 0.96 \\
\hline & No & 107 & 99.1 & 202 & 99.1 & 309 & 99.04 \\
\hline \multirow{3}{*}{$\begin{array}{l}\text { Washing hand } \\
\text { before meal }\end{array}$} & Yes always & 105 & 97.2 & 200 & 98 & 305 & 97.8 \\
\hline & Yes sometimes & 1 & 0.93 & 2 & 1 & 3 & 0.96 \\
\hline & Not at all & 2 & 1.85 & 2 & 1 & 4 & 1.28 \\
\hline
\end{tabular}

Table 2: Clinical and hygiene related characteristics of adult pre- ART and on ART HIVIAIDS patients in Gendewoyn Health Center March to June, 2014. 
The total prevalence of IP both in the pre ART and ART study participants were $42.6 \%$. The overall prevalence of IP in the pre ART was $53.7 \%$ of which helminths were $24 \%$ and protozoans were $29.7 \%$. The most prevalent parasite in the pre-ART study participants were ova of Ascaris lumbricoides (15.7\%) followed by Enteamoeba histolytica (14.8\%). The prevalence of opportunistic parasites in the pre-ART study participants was $11.1 \%$. The most prevalent opportunistic parasites in the pre ART were C. parvum, S. stercoralis and I. belli $4.6 \%, 3.7 \%$ and $2.8 \%$, respectively.

The overall prevalence of IP on the ART study participants was $36.8 \%$. The prevalence of helminths was $14.75 \%$ and the prevalence of protozoans in the ART study participants were $22.1 \%$. The most prevalent parasites were ova of Ascaris lumbricoides (8.8\%) and cyst of Enteamoeba histolytica (7.4\%).

\begin{tabular}{|c|c|c|c|}
\hline \multicolumn{2}{|c|}{ Parasites } & Pre-ART(n=108) & On ART(n=204) \\
\hline \multicolumn{4}{|c|}{ Protozoans } \\
\hline 1 & Trophozite of G. lamblia & $5(4.6 \%)$ & $12(5.9 \%)$ \\
\hline 2 & Cyst of G. lamblia & $3(2.8 \%)$ & $6(2.9 \%)$ \\
\hline 3 & Trophozite of E. histolytica dispar & $4(3.7 \%)$ & $2(1 \%)$ \\
\hline 4 & Cyst of E. histolytica & $12(11.1 \%)$ & $16(7.8 \%)$ \\
\hline 5 & I. belli & $3(2.8 \%)$ & $1(0.5 \%)$ \\
\hline 6 & Criptosporidium spp. & $5(4.6 \%)$ & $8(3.9 \%)$ \\
\hline \multicolumn{4}{|c|}{ Helminths } \\
\hline 1 & Ascaris lumbricoides & $17(15.7 \%)$ & $18(8.8 \%)$ \\
\hline 2 & Strongyloides stercoralis & $4(3.7 \%)$ & $1(0.5 \%)$ \\
\hline 3 & Taenia species & $5(4.6 \%)$ & $4(2.0 \%)$ \\
\hline 4 & H. nana & 0 & $6(2.9 \%)$ \\
\hline 5 & Hookworm & 0 & $1(0.5 \%)$ \\
\hline \multicolumn{2}{|c|}{ Total } & $58(53.7 \%)$ & $75(36.8 \%)$ \\
\hline
\end{tabular}

Double infections

\begin{tabular}{|l|c|c|c|c|}
\hline \multicolumn{2}{|l|}{ Pre-ART patients } & \multicolumn{2}{c|}{ On ART patients } \\
\hline & Frequency & Percent & Frequency & Percent \\
\hline Yes & 4 & 3.7 & 2 & 1.0 \\
\hline No & 104 & 96.3 & 202 & 99.0 \\
\hline Total & 208 & 100.0 & 204 & 100.0 \\
\hline
\end{tabular}

Table 3: Prevalence of IP of single and double infection of adult pre-ART and on ART HIVIAIDS patients in Gendewoyn Health Center, March to June, 2014
The prevalence of opportunistic IP on ART study participants were C. parvum (3.9\%), I. belli (0.5\%) and S. stercoralis (0.5\%). This showed the overall prevalence of opportunistic parasite in pre-ART study participants (11.1\%) was higher than on ART study participants (4.9\%). The overall prevalence of IP in the pre ART (53.7\%) was higher than on ART (36.8\%) study participants.

In the pre-ART study participants $3.7 \%$ of them have double infection whereas on ART study participants $0.5 \%$ had double infection of IP. The study participants who were pre-ART consisted of 68 (62.9\%) with CD4 count $\leq 500$ cells/ul, 40(37.1\%) with CD4 count $>500$ cells/ ul. Almost $65 \%$ of opportunistic parasites in the pre ART group were found with CD4 counts $<=500$ cells /ul. On the ART group 150 (73.5\%) patients were CD4 counts $<500$ cells/ul and $54(26.5 \%)$ were CD4 counts $>500$ cells/ul. 61 parasites with CD4 count $\leq 500$ cells/ul and 14 parasites with CD4 counts $>500$ cells/ul were identified on ART patients.

CD4 count has no significant association with intestinal parasites on ART patients (AOR=1.631, CI 0.673-3.954).

On the multiple logistic regression rural adult pre ART patients of rural residence were 3.766 times $(\mathrm{COR}=3.766$, CI 1.418-10.005) more likely to develop IPI than those urban residences whereas on ART patients rural residents were 1.927 times (COR=1.927, CI 1.0353.972) more likely to develop IPI than urban residents. Accessibility of latrine for both pre ART and on ART patients in the multiple logistic regression analysis showed almost similar association those who did not have latrine were 2 times (pre ART COR=1.718, CI 1.644-4.585, on ART COR=1.496 CI 1.015-3.13) (Tables 3 and 4) more likely to develop IPI than those who have latrine. Pre ART patients with their drinking source of water were from river unprotected were 5 times $(\mathrm{COR}=5.650 \mathrm{CI} 2.122-15.042)$ times more likely to develop IPI than those from protected/tape water sources (Table 3). Whereas on ART patients drinking water source showed great impact for IPI. On ART patients their source of drinking water were from river unprotected were 14 times (COR=14.856, CI 6.82-32.363) more likely to develop

\begin{tabular}{|c|c|c|c|c|c|c|c|}
\hline \multicolumn{2}{|l|}{ Variables } & \multicolumn{2}{|c|}{$\begin{array}{c}\text { Pre-ART } \\
n=108\end{array}$} & \multirow[t]{3}{*}{ COR $(95 \% \mathrm{Cl})$} & \multirow[t]{3}{*}{$P$ valve } & \multirow[t]{3}{*}{ AOR $(95 \% \mathrm{Cl})$} & \multirow[t]{3}{*}{$P$ value } \\
\hline & & \multirow{2}{*}{$\begin{array}{l}\text { Positive } \\
\text { N (\%) }\end{array}$} & \multirow{2}{*}{$\begin{array}{c}\text { Negative } \\
\mathbf{N}(\%)\end{array}$} & & & & \\
\hline & & & & & & & \\
\hline \multirow[t]{2}{*}{ Residence } & Urban & $17(37.8 \%)$ & $28(62.2 \%)$ & $1^{*}$ & & $1^{*}$ & \\
\hline & Rural & $41(65 \%)$ & $22(35 \%)$ & $3.070(1.387-6.795)$ & 0.006 & $3.766(1.418-10.005)$ & 0.008 \\
\hline \multirow[t]{2}{*}{ CD4 count } & $<=500$ & $43(63.2 \%)$ & $25(36.8 \%)$ & $2.867(1.278-6.431)$ & 0.011 & $1.520(1.552-4.185)$ & 0.024 \\
\hline & $>500$ & $15(37.5 \%)$ & $25(62.5 \%)$ & $1^{*}$ & & $1^{*}$ & \\
\hline \multirow[t]{4}{*}{ WHO staging } & Stage 1 & $9(42.8 \%)$ & $12(57.2 \%)$ & $1^{*}$ & & $1^{*}$ & \\
\hline & Stage 2 & $22(55 \%)$ & $18(45 \%)$ & $1.6296(0.174-1.685)$ & 0.289 & $0.732(0.207-2.582)$ & 0.627 \\
\hline & Stage 3 & $17(39.5 \%)$ & $26(60.5 \%)$ & $0.871(00.032-0.351)$ & 0.000 & $0.139(0.038-0.511)$ & 0.003 \\
\hline & Stage 4 & $2(50 \%)$ & $2(50 \%)$ & $1.33(0.103-13.951)$ & 0.884 & $2.848(0.191-10.41)$ & 0.448 \\
\hline \multirow[t]{2}{*}{ Access of latrine } & Yes & $26(48 \%)$ & $28(52 \%)$ & $1^{*}$ & & $1^{*}$ & \\
\hline & No & $32(59 \%)$ & $22(41 \%)$ & $1.566(1.073-3.354)$ & 0.024 & $1.718(1.644-4.585)$ & 0.028 \\
\hline \multirow{2}{*}{$\begin{array}{l}\text { Residence distance } \\
\text { from H/C }\end{array}$} & $<=5 \mathrm{~km}$ & $27(71 \%)$ & $11(29 \%)$ & $1^{*}$ & & $1^{*}$ & \\
\hline & $>5 \mathrm{~km}$ & $31(44.3 \%)$ & $39(55.7 \%)$ & $0.324(0.139-0.754)$ & 0.009 & $0.662(0.229-1.9180$ & 0.447 \\
\hline \multirow{2}{*}{$\begin{array}{l}\text { Source of drinking } \\
\text { water }\end{array}$} & Tape water protected & $16(33 \%)$ & $32(67 \%)$ & $1^{*}$ & & $1^{*}$ & \\
\hline & River water unprotected & $42(70 \%)$ & $18(30 \%)$ & $4.667(2.065-10.548)$ & 0.000 & $5.650(2.122-15.042)$ & 0.001 \\
\hline \multirow{3}{*}{ Shoes wearing } & Yes I wear it always & $9(90 \%)$ & $1(10 \%)$ & $1^{*}$ & & $1^{*}$ & \\
\hline & Yes I sometimes wear it & $39(54.9 \%)$ & $32(45.1 \%)$ & $0.135(0.194-1.199)$ & 0.117 & $0.881(0.277-2.801)$ & 0.830 \\
\hline & No & $10(37 \%)$ & $17(63 \%)$ & $0.065(0.167-1.128)$ & 0.015 & $0.124(0.012-1.323)$ & 0.084 \\
\hline
\end{tabular}

Table 4: Association of socio-demographic and clinical factors of adult pre ART HIVIAIDS patients using binary and multinomial logistic regression with prevalence of intestinal parasite, Gendewoyn Health Center March to June, 2014. 
IPI than from protected water sources. Over all in the multinomial analysis shoe wearing, WHO staging and residence distance showed likely association for intestinal parasite infections.

Associated factors for IP among adult HIV/AIDS patients attending Gendewoyn health center, ART clinic using multiple logistic regression

The multivariate analysis showed that persons whose source of drinking water was from rivers/unprotected were $8(\mathrm{AOR}=8.260$, CI; 4.659-14.642) times more developed IP than those from tape/ protected water sources. The multivariate analysis showed that HAART status has association for intestinal parasite infections. Those pre-ART patients have the probability of developing intestinal parasite infections twice $(\mathrm{AOR}=2.13, \mathrm{CI}, 1.167-3.905)$ than those on ART patients.

HIV/AIDS patients from rural residence developed intestinal parasite infection $2(\mathrm{AOR}=2.292, \mathrm{CI} ; 1.386-3.788)$ times more than urban residents. Concerning CD4 counts HIV/AIDS patients whose CD4 counts $<=500$ cells/ul were 2 ( $\mathrm{AOR}=1.559$, CI; 1.093-2.722) times more likely to develop intestinal parasite infections than those whose CD4 counts $>500$ cells/ul. Those who have toilets developed intestinal parasite infections 2 (AOR=1.802, CI; 1.090-2.975) times more than those who did not have latrines. The overall prevalence of IP in the pre ART (53.7\%) was higher than on ART (36.8\%) subjects. Indicating statistically significant decrease of intestinal parasite in ART patients $(\mathrm{p}<0.006)$

\begin{tabular}{|c|c|c|c|c|c|c|c|}
\hline \multicolumn{2}{|l|}{ Variables } & \multicolumn{2}{|c|}{ On ART $n=204$} & \multirow[b]{2}{*}{$\operatorname{COR}(95 \% \mathrm{Cl})$} & \multirow[b]{2}{*}{$P$ value } & \multirow[b]{2}{*}{ AOR(95\%Cl) } & \multirow[b]{2}{*}{$P$ value } \\
\hline & & Positive N (\%) & Negative $\mathbf{N}(\%)$ & & & & \\
\hline \multirow[t]{2}{*}{ Residence } & Urban & $27(26.5 \%)$ & $75(73.5 \%)$ & $1^{*}$ & & $1^{*}$ & \\
\hline & Rural & $48(47 \%)$ & $54(53 \%)$ & $2.469(1.373-4.441)$ & 0.003 & $1.927(1.035-3.972)$ & 0.025 \\
\hline \multirow[t]{2}{*}{ CD4 count } & $<=500$ & $61(40.6 \%)$ & $89(59.4 \%)$ & $1.958(0.256-1.018)$ & 0.056 & $1.631(0.673-3.954)$ & 0.279 \\
\hline & $>500$ & $14(26 \%)$ & $40(74 \%)$ & $1^{*}$ & & $1^{*}$ & \\
\hline \multirow[t]{4}{*}{ WHO staging } & Stage 1 & $10(71.4 \%)$ & $4(28.6 \%)$ & $1^{*}$ & & $1^{*}$ & \\
\hline & Stage 2 & $38(43.7 \%)$ & $49(56.3 \%)$ & $0.310(0.364-2.233)$ & 0.823 & $0.536(0.185-1.549)$ & 0.249 \\
\hline & Stage3 & $17(30 \%)$ & $46(70 \%)$ & $0.147(0.187-0.987)$ & 0.047 & $0.227(0.083-0.626)$ & 0.004 \\
\hline & Stage4 & $10(25 \%)$ & $30(75 \%)$ & $0.133(0.034-0.521)$ & 0.004 & $0.055(0.011-0.278)$ & 0.000 \\
\hline \multirow[t]{2}{*}{ Access of latrine } & Yes & $35(31 \%)$ & $77(69 \%)$ & $1^{*}$ & & $1^{*}$ & \\
\hline & No & $40(43 \%)$ & $52(57 \%)$ & $1.692(1.024-3.005)$ & 0.032 & $1.496(1.015-3.134)$ & 0.028 \\
\hline \multirow{2}{*}{$\begin{array}{l}\text { Residence distance } \\
\text { from H/C }\end{array}$} & $<=5 \mathrm{~km}$ & $36(44.4 \%)$ & $45(55.6 \%)$ & $1^{*}$ & & $1^{*}$ & \\
\hline & $>5 \mathrm{~km}$ & $39(31.7 \%)$ & $84(68.3 \%)$ & $0.580(0.325-1.036)$ & 0.066 & $0.848(0.400-1.800)$ & 0.668 \\
\hline \multirow{2}{*}{$\begin{array}{l}\text { Source of drinking } \\
\text { water }\end{array}$} & Tape water protected & $16(14 \%)$ & $98(86 \%)$ & $1^{*}$ & & $1^{*}$ & \\
\hline & River water unprotected & $59(66 \%)$ & $31(34 \%)$ & $11.654(5.88-23.110)$ & 0.000 & $14.856(6.82-32.363)$ & 0.000 \\
\hline \multirow{3}{*}{ Shoes wearing } & Yes I wear it always & $11(52.4 \%)$ & $10(47.6 \%)$ & $1^{*}$ & & $1^{*}$ & \\
\hline & Yes I sometimes wear & $32(38.1 \%)$ & $52(61.9 \%)$ & $0.559(0.422-1.427)$ & 0.415 & $0.944(0.432-2.0620$ & 0.872 \\
\hline & No & $32(32 \%)$ & $67(68 \%)$ & $0.434(0.167-1.128)$ & 0.087 & $0.563(0.166-1.905)$ & 0.335 \\
\hline
\end{tabular}

Table 5: Association of socio-demographic and clinical factors of adult on ART HIVIAIDS patients using binary and multinomial logistic regression with prevalence of intestinal parasite, Gendewoyn Health Center, March to June, 2014.

\begin{tabular}{|c|c|c|c|c|c|c|c|}
\hline \multicolumn{2}{|l|}{ Variables } & \multicolumn{2}{|c|}{$\begin{array}{l}\text { Both pre ART and on ART } \\
n=312\end{array}$} & \multirow[t]{3}{*}{$\operatorname{COR}(95 \% \mathrm{Cl})$} & \multirow[t]{3}{*}{$P$ value } & \multirow[t]{3}{*}{ AOR(95\%Cl) } & \multirow[t]{2}{*}{$P$ value } \\
\hline & & $\begin{array}{l}\text { Positive } \\
\text { N (\%) }\end{array}$ & $\begin{array}{l}\text { Negative } \\
\mathbf{N}(\%)\end{array}$ & & & & \\
\hline \multirow[t]{2}{*}{ Residence } & Urban & $44(30 \%)$ & $103(70 \%)$ & & & & \\
\hline & Rural & $89(54 \%)$ & $76(46 \%)$ & $2.741(1.718-4.374)$ & 0.000 & $2.292(1.386-3.788)$ & 0.001 \\
\hline \multirow[t]{2}{*}{ CD4 count } & $<=500$ & $104(47.7 \%)$ & $114(52.3 \%)$ & $2.045(1.225-3.412)$ & 0.006 & $1.559(1.093-2.722)$ & 0.021 \\
\hline & $>500$ & $29(30.8 \%)$ & $65(69.2 \%)$ & $1^{*}$ & & & \\
\hline \multirow[t]{4}{*}{ WHO staging } & Stage 1 & $19(54.3 \%)$ & $16(45.7 \%)$ & $1^{*}$ & & & \\
\hline & Stage 2 & $60(47.3 \%)$ & $67(52.7 \%)$ & $0.754(0.357-1.457)$ & 0.363 & $0.664(0.317-1.391)$ & 0.278 \\
\hline & Stage 3 & $34(32 \%)$ & $72(68 \%)$ & $0.397(0.147-0.558)$ & 0.000 & $0.272(0.1350 .551$ & 0.000 \\
\hline & Stage 4 & $12(27.3 \%)$ & $32(72.7 \%)$ & $0.316(0.075-0.684)$ & 0.008 & $0.231(0.070-0.765)$ & 0.005 \\
\hline \multirow[t]{2}{*}{ HAART STATUS } & ART & $75(36 \%)$ & $129(64 \%)$ & $1^{*}$ & & $1^{*}$ & \\
\hline & Pre-ART & $58(54 \%)$ & $50(46 \%)$ & $1.995(1.243-3.203)$ & 0.004 & $2.135(1.167-3.905)$ & 0.019 \\
\hline \multirow[t]{2}{*}{ Access of latrine } & Yes & $61(37 \%)$ & $105(63 \%)$ & $1^{*}$ & & & \\
\hline & No & $72(49 \%)$ & $74(51 \%)$ & $1.675(1.065-2.633)$ & 0.026 & $1.801(1.090-2.975)$ & 0.111 \\
\hline \multirow{2}{*}{$\begin{array}{l}\text { Residence distance } \\
\text { from H/C }\end{array}$} & $<=5 \mathrm{~km}$ & $70(36 \%)$ & $123(64 \%)$ & $1^{*}$ & & & \\
\hline & $>5 \mathrm{~km}$ & $63(53 \%)$ & $56(47 \%)$ & $1.976(0.318-0.805)$ & 0.004 & $0.727(0.432-1.222)$ & 0.513 \\
\hline \multirow{2}{*}{$\begin{array}{l}\text { Source of drinking } \\
\text { water }\end{array}$} & Tape water protected & $32(20 \%)$ & $130(80 \%)$ & $1^{*}$ & & & \\
\hline & River water unprotected & $101(67 \%)$ & $49(33 \%)$ & $8.374(4.999-14.025)$ & 0.000 & $8.260(4.659-14.642)$ & 0.000 \\
\hline \multirow{3}{*}{ Shoes wearing } & Yes I wear it always & $20(64.5 \%)$ & $11(35.5(\%)$ & $1^{*}$ & & & \\
\hline & Yes I sometimes wear it & $71(45.8 \%)$ & $84(54.2 \%)$ & $0.465(0.364-0.963)$ & 0.035 & $0.679(0.400-1.153)$ & 0.639 \\
\hline & No & $42(33 \%)$ & $84(67 \%)$ & $0.275(0.121-0.627)$ & 0.002 & $0.306(0.126-0.741)$ & 0.043 \\
\hline
\end{tabular}

Table 6: Association of socio-demographic and clinical factors of both pre ART and on ART HIVIAIDS patients using binary and multinomial logistic regression with prevalence of intestinal parasite, Gendewoyn Health Center, March to June, 2014. 
Others like WHO staging, shoes wearing habits and residence distance from health centers have association for intestinal parasite infections (Tables 5 and 6 ).

\section{Discussion}

This study showed high prevalence of intestinal parasite infections in pre-ART and on ART patients. The overall prevalence of intestinal parasite infections in pre ART and on ART patients were $53.7 \%$ and $36.8 \%$, respectively which is higher than a study conducted in Dessie hospital with prevalence of IP infections $39 \%$ for pre ART patients and $17.6 \%$ for on ART patients [13] and higher than a study conducted in Eastern Ethiopia, Hiwot Fana specialized hospital with prevalence of 45.5\% for pre-ART patients and $33.7 \%$ for on ART patients [14]. This may be due to differences in geographic locations and difference in study participants since this study was conducted in rural woreda which may cause the high prevalence. However, the prevalence in this study was lower than a study conducted in Fiche hospital with a prevalence of $70.7 \%$ for pre ART patients and $55.1 \%$ for on ART patients [15]. This difference may be due to Fiche is so high land than the area in which this study was conducted. The difference of the sampling procedure of the two studies might cause the variations.

The parasite distribution showed that in the pre ART patients the distribution of helminths were $24 \%$ which was higher than the distribution of helminthes in Dessie Hospital (7.4\%) and distribution of protozoans were $29.7 \%$ which was lower than the distribution of protozoans in Dessie Hospital (31\%). On ART patients the prevalence of helminthes was $14.75 \%$ which was higher than the distribution reported in Dessie Hospital (5.1\%) and protozoans were 22\% which was higher than the distribution reported in Dessie Hospital (12.5\%).

The most frequently identified parasites in the pre-ART patients were ova of A. lumbricoides (15.7\%) which was higher than a study reported in Dessie Hospital (2.9\%), Nigeria (12.1\%) [16]. and cyst of E. histolityca (11.1\%) higher than study in Nigeria (4\%) and lower than reported in Dessie Hospital (19.1\%). Whereas on the ART patients the most frequently identified parasites were ova of A. lumbricoides (8.8\%) higher than Dessie Hospital (5.1\%) and cyst of E. histolityca lower than Dessie Hospital (2.2\%) [13]. the distribution of C. parvum in pre ART patients was $4.6 \%$ which was lower than study in China (8.3\%) [17] and Nigeria (18.1\%) [16].

In both pre ART and on ART patients' ova of A. lumbricoides is the most frequently identified parasite. But there is difference in the percentage (15.7\% in pre-ART and $8.8 \%$ in ART patients) which may be due to pre ART patients have poor adherence of hygienic practices when they prepare foods and poor adherence on the recommended foods. In addition to this most of pre ART patients do not have awareness about HIV/AIDS prevention, transmission, management and opportunistic prevention, management and their outcome unlike patients on ART. This may cause high prevalence of ova of A. lumbricoides on pre ART patients.

This study showed that HIV/AIDS patients using river water/ unprotected water were more likely to develop intestinal parasite infection which was 8 times more than those who drink tape water/ protected (AOR=8.26; CI 4.659-14.642). This is almost in line with a study conducted in Dessie Hospital (6 times) and Nigeria (5 times) $[13,16]$.

HIV/AIDS patients who were rural resident were 2 times more likely to develop intestinal parasite infections than those urban residents
(AOR=2.292, CI: 1.386-3.788). This is due the rural community has lack of pipe water, lack of knowledge regarding with hygienic water and food when it is compared with urban community.

HIV/AIDS patients who did not have latrine were almost 2 times susceptible for IP than those who had latrine (AOR=1.801, CI: 1.0902.975). This was much lower than in Dessie (8 times) and Nigeria (5 times) $[13,16]$. The difference may be the present study was conducted in rural area which commonly use open defecation.

In terms of CD 4 count; those whose CD 4 counts $\leq 500$ cell/ul, 2 times were more likely to develop IP infections than those whose CD4 counts are $>500$ cells/ul; Which in lines with study in Dessie, Nigeria and China (AOR=1.559, CI: 1.093-2.72) [13,16,17].

HIV/AIDS patients who are pre-ART were twice (2) the probability of developing intestinal parasite than on ART patients.

\section{Conclusion}

This study revealed the importance of examining pre-ART and on ART patients for intestinal parasite infections. Infections with ova of $A$. lumbricoids and $E$. histolityca were the highest distributed parasites for both pre ART and on ART patients and needs care.

Pre ART patients are more susceptible to intestinal parasite infections than on ART patient's particularly rural residents. Hygiene habits like access of latrine and drinking water sources indicating a need for targeted promotion. Opportunistic parasites were highly distributed in pre-ART patients and it was advisable for those patients to start HAART early.

This study makes health professionals regarding the occurrence of these parasites in this population. Routine examination of stool samples for parasitic infections could significantly benefit pre-art and on ART patients for early treatments.

Additionally the study highlights the importance of personal hygiene for preventing intestinal parasite infections for pre-ART and on ART patients especially drinking water source.

\section{Competing Interest}

Authors declare that they have no competing interest in financial, academics, personal ideological, intellectual and commercial interests.

\section{Recommendations}

The findings of this research showed that the prevalence of intestinal parasite infections were high so we recommend clinicians and health professionals to make routine stool examinations for pre ART and on ART patients. The Health Bureau should create awareness towards hygiene components in the rural HIV/ AIDS patients specially about latrine utilizations Rural populations should be aware about their drinking water source and the woreda should construct protected water for these communities. The Health Bureau should address and make these lower CD4 count HIVIAIDS patients regularly examine for intestinal parasite infections.

\section{Authors' Contribution}

All authors have equal contribution for this research starting from design, coordination and analysis of the collected data. All authors read and approved the final manuscript.

\section{Acknowledgement}

First and for most, we would like to express our deepest thanks to Debre Markos University and Gambi College of Medical Science since they allowed us to conduct this research.

Our sincere appreciation is also extended to Goncha Siso Enesie Woreda Health Office, Gendewoyn health center laboratory technicians and ART provide nurses for their support of treatment of IPs positive subjects, for laboratory stool examinations and for questionnaire filled, respectively. 
Citation: Asmare T, Awoke W, Alem G (2017) Prevalence of Intestinal Parasites and Associated Factors among Adult Pre-ART and ART Patients in Goncha Siso Enesie Woreda, East Gojjam, Northwest Ethiopia, 2014. J AIDS Clin Res 8: 734. doi: 10.4172/2155-6113.1000734

\section{References}

1. Kasper L, Braunwald E (2008) Harrison's Principles of Internal Medicine. Harvard Medical School (16 $6^{\text {th }}$ Edn) Gout, Washington DC 35-56.

2. Warren KS, Mahmound AAFED (1984) Tropical and geographical medicine. McGraw-Hill Book Company, New York 23-35.

3. Loukopoulos P, Komnenou A, Papadopoulos E, Psychas V (2007) Lethal Ozolaimus megatyphlon infection in a Green Iguana (Iguana rhinolopa). J Zoo Wildl Med 38: 131-134

4. Dionisio D (2003) Text Book of Atlas of Intestinal Infections in AIDS. Springer Shop Amazon, Italy 1-3

5. Harms G, Feld Meier H (2002) HIV infection and tropical parasitic diseases -deleterious interactions in both directions? Trop Med Int. Health 7: 479-488.

6. UNAIDS (2013) Joint United Nation Program of HIVIAIDS. AIDS Epidemic Update 4.

7. UNAIDS (2013) Joint United Nation Program of HIVIAIDS. AIDS Epidemic Update 6-7.

8. EDHS 2011 (2012) ICF International Addis Ababa, Ethiopia

9. Haque R (2007) Human intestinal parasites. J Health Popul Nutr 25: 387-391.

10. World Health Organization (1987) Prevention and control of intestinal parasitic infections. WHO Tech Rep ser 747-749.
11. Kelly P (1998) Diarrhoea and AIDS: Recent developments in the African setting. Afr Health 20: 16-18.

12. Monica C (2000) District laboratory practice in tropical countries. Cambridge University Press, New York 1: 199-204.

13. Missaye A, Dagnew M, Alemu A, Alemu A (2013) Prevalence of intestinal parasites and associated risk factors among HIVIAIDS patients with pre-ART and on-ART attending Dessie Hospital ART Clinic, Northeast Ethiopia. AIDS Res Ther 10: 7.

14. Teklemariam Z, Abate D, Mitiku H, Dessie Y (2013) Prevalence of intestina parasitic infection among HIV positive persons who are naive and on antiretroviral treatment in Hiwot Fana specialized university hospital, Eastern Ethiopia. ISRN AIDS 2013: 324329.

15. Adamu H, Wegayehu T, Petros B (2013) High prevalence of diarrhoegenic intestinal parasite infections among Non-ART HIV patients in Fitche Hospital, Ethiopia. PLoS ONE 8: e72634.

16. Nat $J$ (2013) Prevalence of intestinal parasite infections among HIV/AIDS patients attending Wudil general hospital Kano State, Nigeria. Int J Pharma Biotech 2013: v3.

17. Tian LG, Chen JX, Wang TP, Cheng GJ, Steinmann P, et al. (2012) Co-infection of HIV and intestinal parasites in rural area of China. Parasit Vectors 5: 36. 